\title{
Technologies Used in Smart Grid to Implement Power Distribution System
}

\author{
Raja Masood Larik*, Mohd Wazir Mustafa \\ Faculty of Electrical Engineering, UniversitiTeknologi Malaysia \\ Corresponding author, email: rmlarik@gmail.com, wazir@fke.utm.my
}

\begin{abstract}
Recently, the debate has been going on about the role of power plus distribution systems, its technologies for future smart grids in power systems. The emerging of new technologies in smart grid and power distribution systems provide a significant change in terms of reduction the commercial and technical losses; improve the rationalization of electricity tariff. The new technologies in smart grid systemshave different capabilities to increase the technological efficiency in power distribution systems. These new technologies are the foreseeable solution to address the power system issues. This paper gives a brief detail of new technologies in smart grid systems forits power distribution systems, benefits and recent challenges. The paper provides a brief detail for new researchers and engineers about new technologies in smart grid systems and how to change traditional distribution systems into new smart systems.
\end{abstract}

Keywords: smart grid, distribution system, technologies, power systems

Copyright $\odot 2015$ Institute of Advanced Engineering and Science. All rights reserved.

\section{Introduction}

New technologies have been tremendously implemented in every field of life and change the technical and operational concepts such as in health, transportation, agriculture, military, industries and power systems [1-3]. In the field of electricity,the wide range of technologies have been developed to cope power efficiencyfor industrial, commercial and residential sectors. In many countries, the electric power distribution network considered as a complex system due to poor visibility, lack of automated analysis and awareness, slow mechanical switching system, etc. These deficiencies lead to blackout and instability in power distribution systems. There are some other inhibiting factors are involved such as growing population, global climate change, capacity limitations. The new smart grid infrastructure requires to address these challenges. The smart grid has emerged with new concept of next generations electric power systems. These smart technologies help to face the next generation challenges of electric power sector and improved reliability, efficiency, and safety through advance automated control and communication. The core power engineering principles coupled with various technologies in smart grid such as smart metering,smart transmissions and power distributions, automation, system optimization, real-time control.The main roles of these technologies in smart grid or power distribution system are smart metering, low-cost communication system, distribution of energy resources and automation. Many projects have been implemented and play a potential role such as use of broadband for communication for distribution applications [4], distributed generation and storage[5], closed loop system using advanced protection [6]. However, these examples are based on single technology in isolation instead of combinedtechnologies solution in smart grid.

This paper main aims to discuss the smart grid systems in the power distribution system its implementation and design requirements. The paper also discussed the existing projects related with power distribution systems and smart grid integration. The main objective of paper as follows:

1. Paper highlights the technologies in smart grid and its power distribution systems.

2. The related work with existing projects in the field presents the clear understanding of smart grid and its related technologies.

3. The paper provides a clear understanding of technologies and smart grid operations for future researchers. 
The remaining paper is organized as follows: section 2 discussed the related work about smart grids in power systems. The detail discussion on smart grids its power distribution systems, technologies in smart grid systems plus integration of smart grid presented in section 3 . The last section concluded the paper with future work.

\section{Related Work}

Various studies have been conducted on smart grids in power systems. In this section, we discuss widely developed projects related with smart grids in power distribution systems. In 2001, the Intel-LiGrid developed an infrastructure for power distributionand integrated with other technologies. This system combined with computing, communication, and electronics technologies for better efficient energy distribution operations. The main objective of this infrastructure is providing the facilities to power transformation, cost efficient network, highquality services, reliable and secure products. The IntelliGrid architecture is based on different projects such as FSM (fast simulation and modeling), DER (distribution energy resources), monitoring system and consumer portal [7]. Advanced distribution automation is another project for creates the distribution systems. It is based on flexible and automated electric system, which handles through open architecture control and communications system. The system has capabilities to provide capacity utilization, customer services options and reliability. The system performance is better in terms of operating costs, storage, distributed generation, restoration time and customer services. In 2005, USA established another modern grid for energy reliability and delivery. Through this program, the grid has new features and services with innovative technologies. The intent of this approach is to accelerate the power grids and nation to modern grids and established the value of developing an integrated suit. The system gives a clear path and offer convincing benefits.

Another effort by U.S department of energy was deployed called GridWise for future power delivery systems [8]. The system main aims to renovate the two-way flow of information and electricity operations in distribution grid operations. The system improves the end user operations and electricity system for customers and suppliers. The smart grid monitoring devices coupled with diagnostic tools and provides maintenance information. In 2005, GridApps formed by concurrent technologies corporation with utility technologies for electric distribution and transmission operations [9]. The technologies in GridApps are categorized into three typesmanagement and monitoring, new devices and system integration. GridWorks is another new program for electricity deliveryto improve the consistency of the system by transformation of important grid mechanisms such as conductors, different types of cables, protective and substations, etc. [9]. The main objective of the system is to enhancingand acceleratingthe existing power systems and improves their efficiency.GridWorksalso takelong term actionsfor adopting new tremendous technologies, approaches and tools. Some other coordinations are also possible including electric distribution, transmission reliability, energy storage devices and GridWise systems. The project DV (distribution vision) 2010, is a combination ofhigh-speed communication, intelligent controllers, and reconfigured feeders and switching devices. Through this system, the customers evadedisruptionsof feeder errors. It is not functional in all feeders somewhat it was used to make premium operating districts surveying consumersfor quality services.

The above discussed projects have positive impact on power distribution systems. The distributions system are designed to satisfy the consumers electricity needs and requirements. Around $80 \%$, the power interruptions are related with distribution systems. The smart grid systems have advanced metering and billing approaches, demand side management, cost effectiveness, energy storage, congestion management, decision support, forecast and human interfaces, etc.

\section{Smart Grid in Power Distribution Systems}

The traditional electricity distribution system has many challenges to enhance its functionality and compete with the market. One of the main challenges is how to improve capability and amount of distribution generation and develop electricity market at customer level. The second challenge is providing safe and cost effective electric distribution network. Traditionally power generation considered as an independent process. To address these 
challenges, smart grid is a novel solution of future infrastructure. The smart grid is modernization system for traditional electric distribution system. It is used to monitor, protect and auto optimize the electric operations from high voltage network to distributed system. The smart grid is a combination of information and communication technologies, distribution and transmission system. The Figure 1, shows the smart grid delivers to consumers with two-way technologies. The emerging concept of smart grid incorporates a plethora of applications such as utilities to integrate, intelligently control innovations, etc.

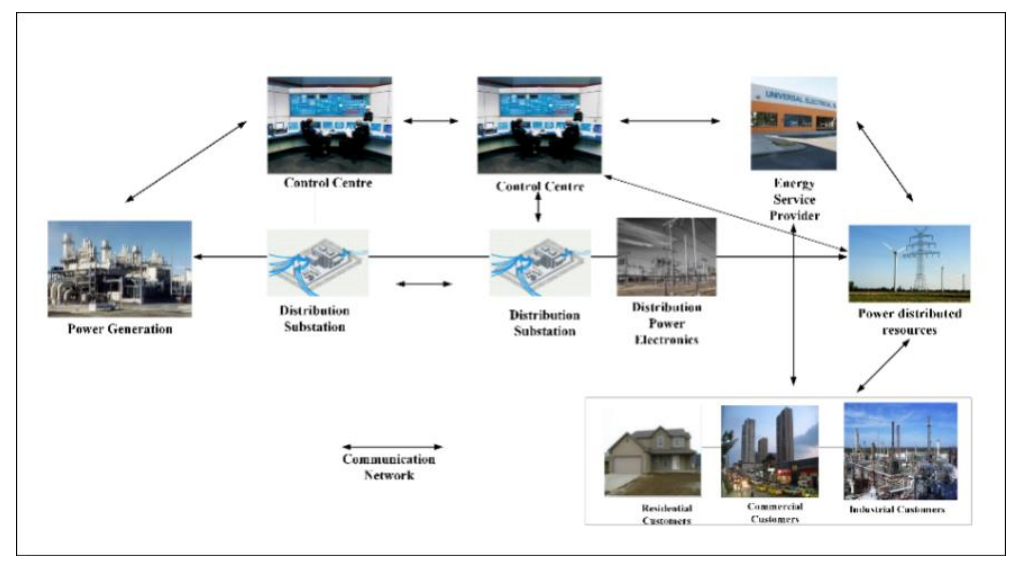

Figure 1. Smart Grid Structure

The smart grid is capable to provide efficient and reliable waytothe power supply with an extensive range of applications andtransmission, distribution plus power consumption. Smart grid replygrid, occursanywheresuch as in case of medium voltage transformer failure and automatically divert the power flow and services. The existing traditional grids are under pressure and faced diversified issues. There are many differences between traditional and smart grids such as two way operations instead of one way operations, self-monitoring capabilities, cyber secure communication, computational intelligence, safe, cost-effective environment. Number of literature discussed the positive features of smart grid for power systems [10-13]. Table 1 shows the comparison of existing traditional grids and smart grids.

Table 1. Traditional and smart grid Comparison

\begin{tabular}{lll}
\hline S/No & Smart Grid & Traditional Grid \\
\hline 1 & Digital operations & Electromechanical operations \\
2 & Two-way communication & One way communication \\
3 & Distributed generation & Centralized generation \\
4 & Pervasive control & Limited control \\
5 & High quality services & Moderate \\
6 & Adaptive & Failures and blackouts \\
7 & Self-monitoring & Manual Monitoring \\
8 & Manual restoration & Self-healing \\
\hline
\end{tabular}

\subsection{Smart Grid Technologies and Distribution System Design}

After a detail discussion of smart grid benefits, it is significant to discuss thesmart grid technologies implications in the distribution system. The important point is that the basic layout and topologyof smart grid matched with traditional grid systems. To clarifying this point, there is a need to examine some design implications for these technologies. The smart grid system offered digital metering with two-way communications capabilities. These digital meters have remotely operation capabilitiesto control voltage and current with record waveforms, real-time rate structures. Furthermore, these new meters are deployed in same traditional meter places without any design implications. In addition, smart meters have more data for processing and lead to efficient asset management operations [14]. The main difference between traditional and 
smart meters isits real time unit recording,balancing ofload during distribution operations, enable automatic demand and response. In the context of design, it is highestin demand per customer due to low voltage and less wire. Figure 2 shows the smart power meter.

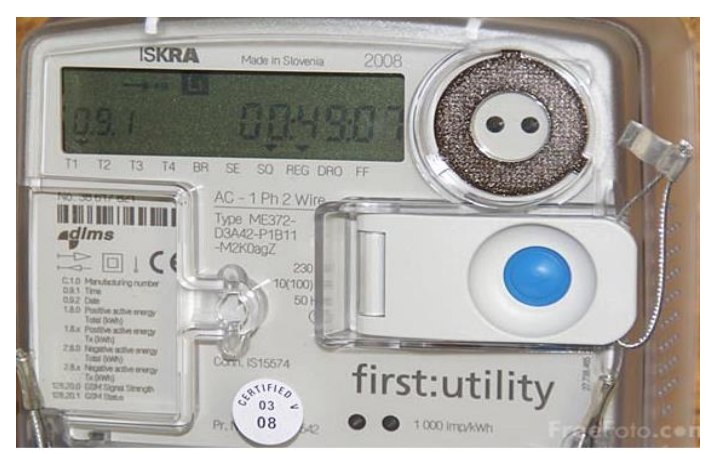

Figure 2. Smart Power Meter

The distribution automation is used for controlling and monitoring the functions on the feeder. In the design perspective, the significant point is its distribution automation especially in terms of switching and protection. The devices for distribution automation are cost effective with intelligent mode. These devices can interrupt faults and monitorscurrent plus voltage moreover reconfigure automatically and achieve goals. The key component of the smart grid is reconfiguring the interconnected networksof feeders. This fact enables through distribution automation with the help of distribution components with enough transfer capacity. Most of the distribution systems are based on single and three phase feeders. The main trunk transmits power far from the substationthroughcenter of feeder area and used single phase for making connection with main trunk to consumer locations. The smart grid do not uses to connect withsubstations to customers in less price, instead it is used to enable the system with flexibility and reconfiguration capability.

Distribution energy resources are based on small sources in terms of storage and connected with distribution system. In low level penetration and in peak demands, the distribution energy resources have not a large effect on system design. Smart grid system has flexible capability with large sources of distribution energy resources. If supply system start to resemble with a small transmission system, it has some design issues like fault current duty andnon-radial power. Some other challenges are also link with the capacity of distribution system and electrical island operations. The distribution system ability is to reliving best power flow constraints and behave like a virtual power plant [15].

\subsection{Integration of Smart Grid}

The smart grid system assimilates the functions of metering infrastructure, distribution automation, and distribution energy resources. The most of the functions are related with communication systems such as information technology systems, processes. After the implementation of smart grid in power distribution system, it will look like mesh interconnected network. The smart grid is operated radially to transmission system but non-radially with distribution energy system. The protection mechanism is smarter in this backbone interconnected network and ensurescoordination. Currently, the distribution systems are designed for power delivery but in smart grids the delivery design are more cost-effective, reliable and flexible and fulfill the customer need and choice. Figure 3 shows the smart grid integration with distribution systems.

There is no doubt about smart grid capabilities and better services in power systems. These technologies provide innovation to achieve affordable, sustainable and reliable power distribution. The smart transmission grids increase the flexibility in operations and expansions and allow the embedded intelligence. Table 2 shows some smart grids projects with description. 


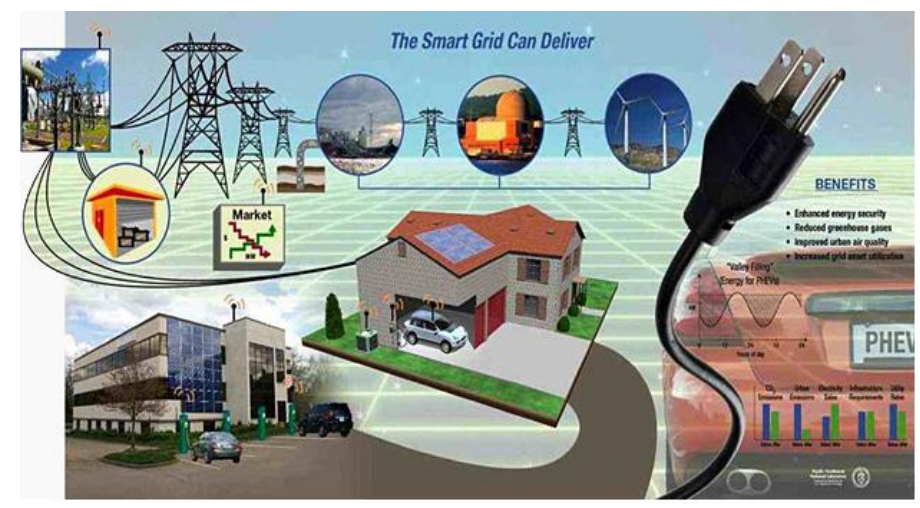

Figure 3. Smart Grid in Distribution system

Table 2. Smart Grid Projects

\begin{tabular}{|c|c|c|c|c|c|}
\hline $\mathrm{S} / \mathrm{No}$ & Project Name & Organization & Period & Description & category \\
\hline 1 & ACEA (Rome)[16] & AceaDistribuzione & $\begin{array}{l}\text { From } \\
2004\end{array}$ & $\begin{array}{l}\text { This is advanced metering project } \\
\text { for improve energy operations with } \\
\text { high accuracy and monitoring } \\
\text { features. }\end{array}$ & $\begin{array}{l}\text { Smart } \\
\text { Metering }\end{array}$ \\
\hline 2 & $\begin{array}{l}\text { Phasor measurement } \\
\text { unit project [17] }\end{array}$ & $\begin{array}{l}\text { American } \\
\text { trsmissioncompany }\end{array}$ & $\begin{array}{l}2010- \\
2012\end{array}$ & $\begin{array}{l}\text { It is fiber optic high speed } \\
\text { communication system to } \\
\text { maximize the competence of } \\
\text { phasor measurement network. }\end{array}$ & $\begin{array}{l}\text { Transmission } \\
\text { Grid }\end{array}$ \\
\hline 3 & EU-DEEP[18] & GDF Suez & $\begin{array}{l}2004- \\
2009\end{array}$ & $\begin{array}{l}\text { It was used for utilities and } \\
\text { address the technical and non- } \\
\text { technical errors of deployment and } \\
\text { distributed energy resources in } \\
\text { Europe. }\end{array}$ & $\begin{array}{l}\text { Distributed } \\
\text { resources }\end{array}$ \\
\hline 4 & $\begin{array}{lr}\text { Large } & \text { scale } \\
\text { demonstration } & \text { of } \\
\text { charging } & \text { electric } \\
\text { vehicles [18] } & \end{array}$ & ChoosEV A/S & $\begin{array}{l}2011- \\
2013\end{array}$ & $\begin{array}{l}\text { It is used to investigate the } \\
\text { possible charging of moving } \\
\text { vehicles. }\end{array}$ & $\begin{array}{l}\text { Integrated } \\
\text { system }\end{array}$ \\
\hline 5 & Grid4EU[18] & ERDF & $\begin{array}{l}2011- \\
2015\end{array}$ & $\begin{array}{l}\text { It aim is to test the real size } \\
\text { innovative system concepts and } \\
\text { technologies for remove barriers. }\end{array}$ & $\begin{array}{l}\text { Integrated } \\
\text { system }\end{array}$ \\
\hline
\end{tabular}

\section{Conclusion}

The traditional power distribution systems have been faced many services and operational challenges. The new smart grid system changed the traditional systems operations and enhances their capabilities with the advanced metering system, communications systems and storage distribution. To implement smart grid systems, the distribution system is reliable with high-quality services and safe from cyber-attacks. The new technologies in smart grid perform cost effective self-healing, low cost operations and offer a variety of services choices to customers. In this paper, we discussed that how the traditional distribution system will adopt the smart grid system without major changings. The smart grid will change the distribution systems without major modifications. Smart grid systems develop a new attractive vision and easily transform the traditional distribution systems.

\section{References}

[1] KN Qureshi, AH Abdullah. Localization-Based System Challenges in Vehicular Ad Hoc Networks: Survey. Smart Computing Review. 2014; 4: 515-528.

[2] KN Qureshi, AH Abdullah. Adaptation of Wireless Sensor Network in Industries and Their Architecture, Standards and Applications. World Applied Sciences Journal. 2014; 30: 1218-1223.

[3] KN Qureshi, AH Abdullah. A survey on intelligent transportation systems. Middle-East Journal of Scientific Research. 2013; 15: 629-642.

[4] T Willie. Broadband over power lines. In Power Line Communications and Its Applications, 2006 IEEE International Symposium. 2006: 1-1. 
[5] MS Jimenez, N Hatziargyriou. Research activities in Europe on integration of distributed energy resources in the electricity networks of the future. In Power Engineering Society General Meeting, 2006. IEEE. 2006: 4.

[6] R Fanning. Distribution Vision 2010: planning for automation. In Power Systems Conference and Exposition, 2004. IEEE PES. 2004: 1692-1693.

[7] NRECA. Report on industry research efforts.

[8] WS Baer, B Fulton, S Mahnovski. Estimating the benefits of the GridWise initiative. DTIC Document. 2004.

[9] R Hassan, G Radman. Survey on smart grid. In IEEE SoutheastCon 2010 (SoutheastCon), Proceedings of the. 2010: 210-213.

[10] B Akyol, H Kirkham, S Clements, M Hadley. A survey of wireless communications for the electric power system. Prepared for the US Department of Energy. 2010.

[11] T Baumeister. Literature review on smart grid cyber security. Collaborative Software Development Laboratory at the University of Hawaii. 2010.

[12] JN Bharothu, M Sridhar, RS Rao. A literature survey report on Smart Grid technologies. In Smart Electric Grid (ISEG), 2014 International Conference. 2014: 1-8.

[13] W Wang, Z Lu. Cyber security in the Smart Grid: Survey and challenges. Computer Networks. 2013; 57: 1344-1371.

[14] D Backer. Power Quality and Asset Management The Other" Two-Thirds" of AMI Value. In Rural Electric Power Conference, 2007 IEEE. 2007: 6-8.

[15] D Pudjianto, C Ramsay, G Strbac. Virtual power plant and system integration of distributed energy resources. Renewable power generation, IET. 2007; 1: 10-16.

[16] Smart Grid Information Clearinghouse. http://www.sgiclearinghouse.org.

[17] X Fang, S Misra, G Xue, D Yang. Smart grid-The new and improved power grid: A survey. Communications Surveys \& Tutorials, IEEE. 2012; 14: 944-980.

[18] V Giordano, F Gangale, G Fulli, MS Jiménez, I Onyeji, A Colta, et al. Smart Grid projects in Europe: lessons learned and current developments. Citeseer. 2011. 